\title{
Grounding and the indispensability argument
}

DOI:

10.1007/s11229-014-0478-2

\section{Document Version}

Accepted author manuscript

Link to publication record in Manchester Research Explorer

\section{Citation for published version (APA):}

Liggins, D. (2016). Grounding and the indispensability argument. Synthese, 193(2), 531-548.

https://doi.org/10.1007/s11229-014-0478-2

\section{Published in:}

Synthese

\section{Citing this paper}

Please note that where the full-text provided on Manchester Research Explorer is the Author Accepted Manuscript or Proof version this may differ from the final Published version. If citing, it is advised that you check and use the publisher's definitive version.

\section{General rights}

Copyright and moral rights for the publications made accessible in the Research Explorer are retained by the authors and/or other copyright owners and it is a condition of accessing publications that users recognise and abide by the legal requirements associated with these rights.

\section{Takedown policy}

If you believe that this document breaches copyright please refer to the University of Manchester's Takedown Procedures [http://man.ac.uk/04Y6Bo] or contact uml.scholarlycommunications@manchester.ac.uk providing relevant details, so we can investigate your claim.

\section{OPEN ACCESS}


Please do not cite this version. The published version is: David Liggins, 'Grounding and the indispensability argument', Synthese 193 (2016), 531-548.

\title{
GROUNDING AND THE INDISPENSABILITY ARGUMENT
}

David Liggins

\begin{abstract}
There has been much discussion of the indispensability argument for the existence of mathematical objects. In this paper I reconsider the debate by using the notion of grounding, or non-causal dependence. First of all, I investigate what proponents of the indispensability argument should say about the grounding of relations between physical objects and mathematical ones. This reveals some resources which nominalists are entitled to use. Making use of these resources, I present a neglected but promising response to the indispensability argument - a liberalized version of Field's response - and I discuss its significance. I argue that if it succeeds, it provides a new refutation of the indispensability argument; and that, even if it fails, its failure may bolster some of the fictionalist responses to the indispensability argument already under discussion. In addition, I use grounding to reply to a recent challenge to these responses.
\end{abstract}

\section{Introduction}

Are there any mathematical objects, such as numbers, functions, or sets? Platonists say 'yes', nominalists say 'no'. Who is right?

One argument for platonism is that we should believe in mathematical objects for the same reason as we believe in microphysical particles: because our best scientific explanations imply their existence. As Hartry Field (1989: 16) puts it:

[I]f our belief in electrons and neutrinos is justified by something like inference to the best explanation, isn't our belief in numbers and functions and other mathematical entities equally justified by the same methodology? After all, the theories that we use in explaining various facts about the physical world not only involve a commitment to electrons and neutrinos, they involve a commitment to numbers and functions and the like.

It will be useful to state the argument as follows: 
(1) Mathematics is indispensable to science: that is, our best explanations imply the existence of numbers and other mathematical objects.

(2) If mathematics is indispensable to science, then there are mathematical objects.

Therefore: there are mathematical objects.

I will call this the indispensability argument. The purpose of this paper is to use the notion of grounding, which has recently surged into prominence, to reassess the debate over the indispensability argument. Consider the following examples:

Socrates' singleton set exists because Socrates does (see Fine 1995: 271-2).

The proposition that dogs bark or pigs fly is true because dogs bark.

Beautiful sculptures are beautiful in virtue of their non-aesthetic features.

These all seem to be cases of dependence: the existence of Socrates' singleton depends on the existence of Socrates, the truth of the proposition depends on the behaviour of animals, and the sculptures' beauty depends on their non-aesthetic features. Moreover, the dependence seems not to be causal in nature. Let us call non-causal dependence grounding. Even if the examples are not genuine - say, because there are no sets, propositions, or beautiful sculptures - they still serve to introduce the concept of grounding: the examples do not need to be believed in order to play that role, only understood. Grounding is closely related to non-causal explanation. The first two examples are explanations, and the third immediately gives rise to one ('Why are beautiful sculptures beautiful? Because of their non-aesthetic features'). These explanations are clearly not causal. Although the term 'grounding' is relatively unfamiliar, the phrase 'in virtue of' and the notion of non-causal explanation are frequently encountered in philosophy. ${ }^{1}$

One of the many controversial questions about grounding concerns its ontology: what sorts of things are grounds and grounded? For convenience, I will assume that grounding is a relation between facts, so that (for instance) the fact that $a$ bears $\mathrm{R}$ to be $b$ might be grounded by the fact that $a$ has the property of Fness; in other words, the obtaining of relation R between $a$ and $b$ might be grounded by $a^{\prime}$ s having the property of Fness. (Rosen 2010 takes this view of grounding.) But what I

\footnotetext{
${ }^{1}$ For introductions to grounding, see Correia and Schnieder 2012, Clark and Liggins 2012, and Trogdon forthcoming.
} 
say could be rephrased to conform to other theories, for instance, the theory that grounding-talk should be regimented using a sentential connective (' $a$ bears $\mathrm{R}$ to $b$ because $a$ is $\mathrm{F}^{\prime}$ ). I will sometimes help myself to this way of speaking.

Let me from now on use 'platonist' as shorthand for 'platonist who endorses the indispensability argument'. I'll first of all consider the metaphysical commitments of platonists, because this reveals some resources which nominalist opponents of the indispensability argument are entitled to use (section 2). More specifically: I will argue that platonists should posit nominalistic grounds of relations between physical and mathematical objects. Then I'll build on this to present a neglected response to the indispensability argument (section 3). The response is a liberalized version of Field's. In brief, where the platonist appeals a relation between a physical and a mathematical object in explaining some phenomenon, and so should posit a nominalistic fact in virtue of which this relation obtains, the nominalist can instead appeal to this nominalistic fact in explaining the phenomenon. In this way, they may seek to undermine premiss (1) of the indispensability argument. I'll then discuss the significance of this strategy. In particular, I will argue that the response is promising and avoids the main objections to Field's programme; and that, even if the response fails, its failure may bolster some of the fictionalist responses to the indispensability argument already under discussion, those associated with Melia and Yablo (section 4). Finally, I'll use the discussion in section 2 to deal with a recent challenge to these responses (section 5). So I both praise a neglected response and help defend a not-so-neglected response.

Before proceeding, I should mention that other formulations of the indispensability argument are available. Some of these include ambitious general claims. For instance, Resnik's version of the argument involves both confirmational holism - the claim that 'the observational evidence for a scientific theory bears upon its theoretical apparatus as a whole and not upon its individual hypotheses' - and naturalism - the claim that 'natural science is our ultimate arbiter of truth and existence' (Resnik 1997: 45). My version of the indispensability has the advantage of avoiding these bold assertions. It is close to Colyvan's much-discussed formulation (Colyvan 2001: 11), but it avoids a distracting epistemic element of that version. As stated by Colyvan, the argument's conclusion is about what we ought to believe - but I take it that the indispensability argument was meant to show that there are mathematical objects. ${ }^{2}$

\footnotetext{
2 A footnote of Colyvan's (2001: $12 \mathrm{fn}$. 19) suggests he would have no quarrel with my formulation. On the appeal to confirmational holism, see Morrison 2012. On naturalism, see Williamson 2011, 2011 a.
} 


\section{The metaphysical commitments of proponents of the indispensability argument}

Proponents of the indispensability argument must claim that some mathematical objects are related to some non-mathematical objects, such as towns and insects. This is because they believe that some of our best explanations involve claims about the obtaining of such relations. For instance, Aidan Lyon (2012: 562-3) seeks to explain why no-one has ever walked across Königsberg crossing each bridge exactly once by claiming that Königsberg's graph has a particular mathematical property (the property of being non-Eulerian). So in Lyon's view, the city and the graph are related by the has graph-theoretical-structure relation.

In virtue of what are the city and the graph so related? I am not asking for a causal explanation: rather, I am asking what grounds the obtaining of the relation.

The answer to the question is clear. Lyon should say that the relation obtains in virtue of the physical structure of the city. (I suppose this is the property of containing certain locations connected by such-and-such paths.) The obtaining of the relation is grounded in the city's physical structure. This is why destroying some bridges, or building more, affects which graph belongs to the city.

What about cases of physical quantities, such as mass and duration? Alan Baker (2005) offers to explain facts about the life-cycles of certain insects by claiming that they are related to numbers: the insects are related to numbers by the has-life-cycle-in-years-of relation. Other proponents of the indispensability argument are likely to claim that tables are related to numbers by the has-mass-inkilograms-of relation. How are they to explain the obtaining of these relations? Let us call these relations 'quantitative relations', and call a property (or relation) 'nominalistic' just in case it could be possessed (or obtain) even if nominalism were true. ${ }^{3}$ Call a property or relation 'platonistic' just in case it is not nominalistic. I will examine three options concerning the explanation of why quantitative relations obtain:

(a) There is no explanation.

\footnotetext{
${ }^{3}$ Some philosophers will object to this definition by claiming that (i) if platonism is true, nominalism is metaphysically impossible; and (ii) it is a trivial matter how things would be were some metaphysical impossibility the case. But neither of these claims should command our confidence; still less should their conjunction. In particular, (i) lacks a secure motivation and there are serious arguments against it; and the Lewis-Stalnaker semantics for counterfactuals - the usual motivation for (ii) - is not beyond question. I cannot cite all the relevant literature here, but regarding (i), see Miller 2010; regarding (ii), see Nolan 1997, section 2. (Philosophers who object the definition given in the text, whether on these grounds or others, may think of nominalistic properties and relations as those that do not 'involve' mathematical objects. Thanks to an anonymous referee for this alternative definition.)
} 
(b) The obtaining of quantitative relations is explained by the objects' possession of nominalistic properties.

(c) The obtaining of quantitative relations is explained by the objects' standing in nominalistic relations.

I will take these options in turn. My goal is to show that (b) is preferable to (a) and (c). Extra complications arise if we consider quantities which are not monadic (such as distance), or quantities which are metaphysically dependent on other quantities (for example, it is plausible that an object's density is grounded in its mass and volume). To avoid these complications, I will concentrate on the example of mass.

Option (a) is to deny that there is any explanation of why the mathematical and the nonmathematical objects are related. The obtaining of the relation is metaphysically fundamental, in the sense that the relation does not obtain in virtue of anything. The same goes for non-monadic fundamental quantities. Where metaphysically dependent quantity-relations (such as has-density-inkilograms-per-cubic-metre-of) are concerned, their obtaining is ultimately explained by the obtaining of metaphysically fundamental quantity-relations. ${ }^{4}$

I suspect that our pre-theoretical view is inconsistent with option (a). As Baker 2003 points out, many of us tend to think that mathematical objects do not make a difference to the physical world. Baker interprets the sort of difference-making at issue here as counterfactual dependence: 'if there were no mathematical objects, then the physical world would be just the same'. This is worth discussing, since some of the authors he discusses put the point in counterfactual terms. But perhaps the difference-making in question is better understood as metaphysical dependence - the idea that things do not have their physical properties in virtue of anything to do with mathematical objects. 'Makes no difference' arguments deserve reassessment in the light of recent discussions of grounding, though I cannot undertake that project here. My point is that option (a) seems to imply that mathematical objects do make a difference to the physical world. For presumably any platonist who adopts (a) will claim that facts about mass are facts about relations to numbers: what else could they be? But then numbers do make a metaphysical difference to the physical world. So our pretheoretical view seems to be inconsistent with option (a).

\footnotetext{
${ }^{4}$ This resembles the view typically attributed to Pythagoras. It is similar to the position Field (1989: 186-93) calls 'heavy duty platonism' - but not quite the same. Field (1989: $181 \mathrm{n}$. 16) insists he is talking about predicates, not properties, and he envisages the alternative to 'heavy duty platonism' to involve an appeal to representation theorems (187), whereas that does not follow from the view under discussion here. So my option (a) is not exactly Field's 'heavy duty platonism'.
} 
There is also a more theoretical reason for platonists to reject (a). It seems to involve the platonist in an arbitrary choice of scale. Which mass-relation obtains? The has-mass-in-kilograms-of relation, the has-mass-in-pounds-of relation, or some other relation, perhaps not corresponding to any scale of mass actually in use? Any choice of scale is arbitrary. To give any one unit of measurement priority here is unattractive (see e.g. Crane 1990): we would require a strong argument to show us that one scale for measuring mass is metaphysically privileged. And the same goes for time, and other quantities.

To avoid this problem, the proponent of option (a) could say that for every possible scale of mass, the corresponding mass-relation is instantiated: all possible mass-relations obtain. But then there would be some striking regularities requiring explanation: for instance, we would need an explanation of why everything that bears the has-mass-in-kilograms-of relation to the number 8 bears the has-mass-in-pounds-of relation to the number 17.6. It is hard to see how to give any satisfactory answer that is consistent with option (a). To explain this phenomenon, one must say that the table bears the has-mass-in-kilograms-of relation to the number 8 because it bears the has-mass-in-pounds-of relation to the number 17.6; or that the table bears the has-mass-in-pounds-of relation to the number 17.6 because it bears the has-mass-in-kilograms-of relation to the number 8 ; or say that the obtaining of both relations depends on some third thing. But none of these options is consistent with option (a). The problem of arbitrariness remains.

Option (b) claims that objects bear quantitative relations to numbers in virtue of possessing nominalistic properties. For instance, there will be a nominalistic property has-mass-8-kilograms: and it is because the table that property that it bears the has-mass-in-kilograms relation to the number 8 . (It is crucial that has-mass-8-kilograms is not the property of bearing the relation has-mass-inkilograms-of to the number 8; for then it would not be nominalistic.) Things will be more complicated where non-monadic quantities are involved: for instance, the obtaining of a three-place distance relation between two physical objects and a number will be explained by the obtaining of a twoplace nominalistic distance relation between the physical objects. The obtaining of metaphysically dependent quantity-relations will be ultimately explained by the obtaining of nominalistic properties such as has-mass-8-kilograms (and nominalistic relations, in the case of dependence on a fundamental non-monadic quantity).

This option comports with the metaphysics of quantities which tends to be assumed by metaphysicians working in the Lewisian tradition, in that it assumes that there is a nominalistic property for every mass (cf. Hawthorne 2006). Since this property is scale-independent, option (b) escapes the problem of arbitrariness. The property has-mass-8-kilograms is the very same property as 
has-mass-17.6-pounds, so no particular scale of measurement is privileged. I therefore take (b) to be superior to (a).

The final option on my list is to explain the obtaining of quantitative relations by appeal to the obtaining of nominalistic relations. In the case of mass, these nominalistic relations are likely to be comparative relations, such as is-more-massive-than and is-just-as-massive-as. Where non-monadic fundamental quantities are concerned, the obtaining of the relations is explained by appeal to nominalistic relations of greater adicity than the quantity in question. The same nominalistic relations are employed to explain the obtaining of metaphysically dependent quantity-relations (such as has-density-in-kilograms-per-cubic-metre-of).

If any of the options is implicit in the literature on measurement (e.g. Nagel 1931), it is option (c). Often it is coupled with an appeal to representation theorems. These are mathematical results that show that if the distribution of the comparative relations satisfies certain constraints, then there is a function from physical objects to numbers having the properties one requires of a measurementfunction - for instance, that if $x$ bears the is-more-massive-than relation to $y$, then the image of $x$ is greater than the image of $y$. When Field writes about option (c), he combines it with the idea that proving representation theorems shows that quantitative relations are, as he puts it, 'conventional relations' (Field 1989: 188), but I will set that addition to one side.

There are two well-known problems with option (c). First, the assumptions needed to prove the representation theorems seem clearly false (Mundy 1987: 32-3). For instance, the usual representation theorem for mass requires the assumption that for any two objects there is an object that is exactly as massive as the two of them put together - but this assumption seems clearly false.

The second problem goes deeper, in that it applies to option (c) even if the appeal to representation theorems is dropped. The problem is that the distribution of mass does not supervene on the distribution of the relations as is-more-massive-than and is-just-as-massive-as (see Melia 1998: 68). This means it is improbable that the obtaining of these comparative relations can explain the obtaining of relations such as has-mass-in-kg-of. ${ }^{5}$ To see the failure of supervenience, consider two scenarios. In the first scenario there are just two objects: one has mass 1 kilogram, the other has mass 2 kilograms. In the second scenario there are again just two objects, but they have masses 1 kilogram and 3 kilograms this time. There is no way to distinguish between these scenarios using just is-more-massive-than and is-just-as-massive-as (cf. Hawthorne 2006: 230-1).

\footnotetext{
${ }^{5}$ See Rosen 2010: 118 on the relation between grounding and necessitation.
} 
Proponents of option (c) could try to get round the problem by introducing additional comparative relations, such as is-twice-as-massive-as. But then a scenario with just two objects of masses 1 and 2 kilograms would be indiscernible from a scenario with just two objects with masses 2 and 4 kilograms - whereas these possibilities are distinct (cf. Liggins 2003: 207).

The metaphysics of quantities deserves a much fuller discussion than I have provided here. For instance, I have not taken into account the latest contributions, such as Dasgupta 2013. So my conclusion here is provisional: proponents of the indispensability argument should prefer option (b) to options (a) and (c). Even if it turns out that (c) is as least as good as (b), my main point here should stand: platonists should give nominalistic explanations of the obtaining of quantitative relations. (Indeed, the same goes for any platonist who believes that quantitative relations obtain not only those who endorse the indispensability argument.). I will now show how nominalists can use this result to help them reply to the indispensability argument.

\section{Nominalist responses to the indispensability argument}

What sorts of responses to the indispensability argument are available to nominalists? Following Colyvan (2010), let us distinguish two 'roads' for nominalists to take.

The hard road is to refuse to accept (1). Nominalists who take the hard road reply offer alternative explanations which do not imply the existence of mathematical objects, and argue that these are at least as good as the explanations the proponents of the indispensability argument claim to be the best. This is the project of nominalizing science.

The easy road is to refuse to accept (2). Nominalists who take the easy road argue that, even if (1) is true, it does not follow that there are mathematical objects. Perhaps the most prominent easy road strategy is to argue that mentioning mathematical objects enhances our expressive power rather than our explanatory power:

Numbers enable us to make claims which ... we ... would otherwise have trouble putting into words. (Yablo 2002: 230) ${ }^{6}$

[M]athematics is used [in science] simply in order to make more things sayable about concrete objects. (Melia 1998: 70-1)

\footnotetext{
${ }^{6}$ Yablo cannot be straightforwardly classed as a nominalist, but his view is close enough to abstract expressionism to be worth mentioning here.
} 
Call this form of easy road response abstract expressionism.

If the indispensability argument is formulated as above, nominalists who wish to reply to it must take either the easy road or the hard road. There are no other options.

'Easy road' and 'hard road' are Colyvan's terms (Colyvan 2010). The hard road is so called because everyone agrees it's hard; the easy road is so called, not because everyone agrees it's easy, but because its proponents think it's easier than the hard road: they think they are not required to pursue a nominalization programme. Colyvan himself denies that it is easier, and argues that easy road nominalists need to undertake something like Field's programme (see Colyvan 2010). I'll return to this in section 5 .

The best-known version of the hard road is Hartry Field's, first set out in his Science without Numbers (1980). I take it that extensive discussion of Field's programme has uncovered serious objections to Field's strategy for nominalizing science. (I will mention the most important ones in section 4.) For the rest of this paper, I will assume that Field's programme does not succeed.

It is tempting to identify the hard road with Field's programme. Discussions of the indispensability argument often move straight from the failure of Field's programme to discussion of the easy road (for instance, Balaguer 2011 does this). But do the difficulties of Field's programme mean that the easy road is the only one for nominalists to take? The following quotation from Field is revealing:

The basic strategy of Science without Numbers was to take physical theories stated in terms of numerical functors and try to restate them in terms of comparative predicates instead. (Field 1989: 130)

For example, Field's treatment of distance employs the predicates 'Cong' and 'Bet'. Informally, ' $x y$ Cong $z w$ ' means 'length $x y$ is congruent to length $z w^{\prime}$, and ' $x$ Bet $y z$ ' means ' $x$ is between $y$ and $z$ ', where $x, y, z$, and $w$ are space-time points. Now there is nothing in the definition of the hard road given above which requires the hard road nominalist to introduce comparative predicates and to state their explanations in terms of them. It is far from obvious that taking the hard road requires the nominalist to adopt Field's 'basic strategy'. Field's programme therefore represents only one lane on the hard road.

The discussion in the preceding section revealed some new resources for nominalist opponents of the indispensability argument to use. As we saw, part of Lyon's explanation of why no-one has 
ever walked across Königsberg crossing each bridge exactly once is that Königsberg is related to a particular graph by the has graph-theoretical structure relation; and I argued that Lyon should explain why this relation obtains by saying that the city has a particular physical structure. If so, then he should have no objection to nominalists citing the physical structure of the city in their explanations. Nominalists can therefore offer an alternative explanation of the original phenomenon: they can claim that no-one has ever walked across Königsberg crossing each bridge exactly once because the city has a certain physical structure.

I will now introduce some notation to express these ideas. Let ' $k$ ' pick out Königsberg, and let 'g' pick out the particular graph just mentioned. Furthermore, let the predicate 'S' express the hasgraph-theoretical-structure relation. Then the platonist claims:

kSg.

As we have seen, the platonist should claim that the city bears this relation to this graph in virtue of having a nominalistic property (the property of having a particular physical structure). Let the predicate 'S-g' express this property. Then the platonist's claim is:

\section{kSg because S-gk}

In explaining the phenomena which platonists appeal to mathematical objects to explain, nominalist can use predicates such 'S-g'. Where the platonist appeals to the fact that $\mathrm{kSg}$, the nominalists can appeal to the fact that S-gk.

In the case of physical quantities, I argued that platonists should say that the table bears the hasmass-in-kilograms relation to the number 8 because the table has the nominalistic property has-mass8-kilograms. Where the platonist explains some phenomenon by appeal to the relation holding between the table and the number, the nominalist can seek to explain it by saying that the table has the nominalistic property. And similarly with other quantities.

The strategy generalizes. Suppose that platonist explains some phenomenon by appeal to a relation R relating a physical object c to a mathematical object o ('cRo'). The nominalist can explain the phenomenon by appealing to a nominalistic property - specifically, the the nominalistic property of $\mathrm{c}$ to which platonists should appeal in explaining why cRo. Let ' $\mathrm{R}-\mathrm{o}^{\prime}$ pick out this property. Then, where the platonist's explaination is ' $\mathrm{CRo}^{\prime}$, the nominalists's explanation is 'R-oc'. (And similarly in polyadic cases: I will give an example in the following section.) Call this strategy 
the fast lane of the hard road, or the fast lane for short. In a nutshell: platonists should posit nominalistic grounds of relations between physical and mathematical objects; the fast lane is the strategy of using these in explanation instead of Field's comparative predicates.

I am assuming that in explaining why a physical object bears some particular relation to a mathematical object, platonists will appeal to only one physical property of the object: but if there are many possible properties for platonists to appeal to, that provides correspondingly many alternatives for travellers on the fast lane to try out.

The fast lane is a neglected option. An earlier version was proposed by Richard Creath: see Creath 1980 ('the strategy will be to absorb the numerical expression into the predicate' (314)). Later in his paper, Creath appeals to representation theorems, but he thereby opens his approach to objections similar to those mentioned above. The fast lane nominalist has no need to invoke representation theorems. Another difference is that grounding plays no role in Creath's discussion: this means his strategy lacks the generality of the fast lane. Meyer 2002: 306 mentions something similar to the fast lane strategy when he talks of regimenting science by appeal to (for instance) 'that mass property in virtue of which [an object is related to a number by a mass relation]'. However, 'in virtue of' is dropped in Meyer's subsequent formalization and discussion. The fast lane is also reminiscent of Horgan 1984.

There is an interesting exegetical question: why did Field confine himself to using comparative predicates rather than helping himself to fast lane resources? Davidson (1965) objects to the postulation of infinitely many 'semantic primitives' on the grounds that such a language would be unlearnable. One might have expected Field to have been motivated by this argument, but in fact he declines to endorse it (Field 1989: 197). In any case, the Davidsonian worries are dubious: see Horgan 1989: section 3 for illuminating discussion of a parallel example. A clue to Field's thinking is found in his discussion of relationism about space. Field examines a theory which uses four-place predicates ' $\mathrm{C}_{2}{ }^{\prime},{ }^{\prime} \mathrm{C}_{3}$ ', etc. where ' $\mathrm{C}_{2}$ ' applies to $x, y, z$ and $w$ iff the distance from $x$ to $y$ is twice that from $z$ to $w,{ }^{\prime} \mathrm{C}_{3}$ ' applies to $x, y, z$ and $w$ iff the distance from $x$ to $y$ is three times that from $z$ to $w$, and so on. Field says that his objection to the theory is not that it employs infinitely many primitive predicates, but that we cannot 'recursively characterize them using finitely many axiom schemata'; we cannot explain what these primitive predicates 'have to do with each other' (1989: 198). Is there an objection to fast lane nominalism here? If the argument I have given above is correct, the predicates the fast lane nominalist uses should also be used by platonists, when they explain what 
grounds the obtaining of certain relations. So any objection here arises for both nominalists and platonists. Moreover, it is not clear that either party has an advantage when it comes to replying. ${ }^{7}$

\section{The fast lane: discussion}

Where platonists explain phenomena by appeal to relations between physical and mathematical objects, the fast lane nominalist explains these phenomena by appeal to nominalistic properties of the physical objects. The fast lane explanations are superior in two important respects. Firstly, they cite the causes of the phenomena explained. When the rabbit is placed on the scales and the pointer swings round to the numeral ' 8 ', that is an effect of the rabbit's mass: the pointer swings to that position because the rabbit has-mass-8-kilograms. Secondly, the fast lane explanations avoid any arbitrary choice of scale, because they appeal to nominalistic properties, and these are scaleindependent. ${ }^{8}$

Some might argue that appealing to mathematical objects leads to greater unification: various disparate phenomena can all be traced back to the same (for instance) arithmetical truths (cf. Colyvan 2001: 83). But if relations between mathematical objects and numbers are not fundamental, then the appearance of unification is illusory, since mathematical objects are not the sources of the phenomena in question - the sources are the underlying nominalistic properties.

Field's programme has received many powerful objections. An important advantage of the fast lane strategy is that it is immune from these objections, as I will now explain.

One group of objections to Field concerns his postulation of space-time points. Resnik (1985) argues that Field is not entitled to invoke space-time points because they raise the same epistemological problems as mathematical objects. And Melia (1998: section 2) argues that Field's explanations in terms of space-time points invoke causally irrelevant objects, and rest on an arbitrary selection. Now Field is led to posit space-time points as part of his account of distance because his 'basic strategy' is to use comparative predicates: if there are sufficient space-time points, then distance-claims can be restated using the comparative predicates 'Cong' and 'Bet' by mentioning intermediate space-time points (see Field 1980: chapters 3 and 6, Melia 1998: section 2). Nominalists on the fast lane do not restrict themselves to using comparative predicates. Where the platonist explains some phenomenon with the claim that $\mathrm{a}$ and $\mathrm{b}$ are related to the number 3 by the

\footnotetext{
${ }^{7}$ Note that I do not claim that the fast lane philosopher should hold that 'S-g' and suchlike are semantically primitive predicates. Neither do I claim that platonists should hold this either. Thanks to an anonymous referee for pressing me to be clearer on this.

${ }^{8}$ Field (1980: ix, 6, 43, 45-6; 1989: 18-19) claims these two virtues for his own reformulations of science. But see Melia 1998 for criticism.
} 
three-place distance-in-metres relation, the fast lane nominalist explains it by claiming that $\mathrm{a}$ and $\mathrm{b}$ are related by a two-place nominalistic distance relation ('are-3-metres-apart', let us call it, where the hyphens indicate that ' 3 ' does not occupy an argument place). Fast-lane resources mean there is no need for the nominalist to appeal to space-time points in formulating distance claims. This deals with Melia's objection. And although Resnik's objection may damage Fieldian nominalism, it has no force in the present dialectical context. My question is whether nominalists have a good response to the indispensability argument: as a response to the indispensability argument, the fast lane does not incorporate any argument for nominalism. Field makes a case for nominalism and thereby exposes himself to Resnik's attack, whereas the fast lane philosopher's task is to respond to the indispensability argument, and so Resnik's attack is irrelevant. Anyway, Field (1989: 46-7, 67-73) makes a strong case for the good epistemic standing of space-time points, thereby repelling Resnik's attack directly.

Another leading objection to Field maintains that Field's method of nominalizing Newtonian gravitational theory cannot be used to nominalize quantum mechanics (Malament 1982). As we have seen, one notable feature of the fast lane is that it offers an entirely general method for freeing our explanations of references to mathematical objects. The objection therefore fails to touch the fast lane.

Other objections to Field stem from his appeal to representation theorems. Melia (1998: section 3) argues that Field's representation theorem for mass will not be provable unless he posits infinitely many massive bodies. ${ }^{9}$ Shapiro's much-discussed (1983) objection also targets the appeal to representation theorems, as does Melia 2006. Since the fast-lane nominalist makes no appeal to representation theorems, they escape all such objections. Field is led to appeal to representation theorems because of his insistence on using comparative predicates; there is no need for the fastlane nominalist to invoke these theorems at all. ${ }^{10}$

We have now seen that the fast lane escapes the principal objections to Field's programme. Above, I argued that the fast lane explanations have two important advantages over the explanations offered by platonists. I conclude that the fast lane is worthy of serious attention.

It is too early to conclude that the fast lane overcomes the indispensability argument. Explanations involving generalizations form an obstacle to the strategy. Suppose, for instance, that we wish to explain the motion of some objects in a particular domain, and that part of our

\footnotetext{
${ }^{9}$ Melia's point echoes Mundy's criticism of appeal to representation theorems, mentioned in section 2 above. ${ }^{10}$ See Liggins 2012, section 3 for related discussion.
} 
explanation is that each of the objects has a mass. With a two-place predicate ' $\mathrm{M}$ ' expressing a platonistic mass-relation this is easy to formulate:

$$
\forall x \exists y x \mathrm{M} y
$$

Fast-lane nominalists cannot use that predicate. Instead, they have a range of one-place predicates picking out different nominalistic mass-properties, 'M-1', 'M-2', 'M-3', etc. But no finitely long disjunction of these captures the generalization. For instance, consider:

$\forall x(\mathrm{M}-1 x \vee \mathrm{M}-2 x \vee \mathrm{M}-3 x)$

This is stronger than required because it excludes the possibility that one of the objects satisfies 'M$4^{\prime}$.

Better would be:

$\forall x \exists y \mathrm{M}-y x$

but how are the first quantifier and the variable it binds to be interpreted? Note that we have quantification not into name position or predicate position, but into sub-predicate position; and the nominalist cannot interpret this as objectual quantification over numbers. Perhaps the fast lane nominalist can maintain that the quantification is best interpreted as substitutional. Or perhaps they can maintain that it is neither objectual nor substitutional, and supply some further elucidation of its nature. (It has never been shown that all quantification is either objectual or substitutional. Here I echo Schiffer 2003: 90 and Williamson 1999: 262-3; see also Field 1984, Field 1989: 244-7.) Such a project will presumably involve an account of the structure of the predicates 'M-1' etc. It is intuitively clear which generalization is being invoked; the problem is to come up with an acceptable formulation of it. This requires identifying a suitable language, one with richer resources than predicate calculus, and explaining how it functions. ${ }^{11}$

\footnotetext{
${ }^{11}$ Instead of ' $\forall x \exists y \mathrm{M}-y x^{\prime}$, the fast lane philosopher might try to express the claim that each of the objects has a mass using ' $\forall x \exists F(\Phi(F) \wedge F x)^{\prime}$, where ' $\Phi(F)^{\prime}$ ' holds just in case ' $F$ ' ascribes a mass-property. This option also goes beyond the resources of predicate calculus - even second-order predicate calculus. It raises similar issues to the formulation in the text. Thanks to an anonymous referee for this suggestion.
} 
There is work here for the fast lane philosopher to do, but there is also reason for optimism that it can be accomplished. Many philosophers are accustomed to thinking of quantification as quantification into name position, but it is arguable that natural language contains several additional varieties of quantification, such as quantification into general term position (Künne 2006, section V) and quantification into 'that'-clause position, understood as distinct from singular term position (Rosefeldt 2008). There is no consensus over the functioning of these expressions; greater understanding of the varieties of natural language quantification and how they function promises to supply inspiration to fast lane philosophers. ${ }^{12}$

Another challenge to the fast lane strategy is that it threatens to prove too much. Suppose one philosopher claims that my belief that Mal's action is wrong is explained by the wrongness of Mal's action. Since it is widely acknowledged that moral properties, if there are any, depend on non-moral properties, the philosopher is likely to agree that Mal's action is wrong in virtue of possessing nonmoral property N. Must we then reject the moral explanation and claim that my belief is explained, not by the wrongness of Mal's action, but by its possessing N? This claim moves us towards moral scepticism. To give another example, it is common to hold that there are mental states and they are possessed in virtue of physical states. Does the fast lane lead to scepticism about the existence of mental states by showing that the underlying physical states do all the explanatory work? ${ }^{13}$

In response, the fast lane nominalist might present relevant differences between the cases that prevent the fast lane strategy from over-generalizing. For instance, perhaps the best argument for the existence of mental states does not parallel the indispensability argument: it may be that, rather than positing them as the best explanation of some phenomena, we have introspective evidence for their existence. If so, then the counterpart of the fast lane strategy, even if it undercuts the 'best explanation' argument, will not threaten realism about the mental.

Another possible response is to question the assumption that we should be realists about the mental, moral, and other areas. The worry is that the fast lane strategy proves too much - but who is to say how much is too much? The existence of mental states is not a datum, but a subject of philosophical controversy. So too is the existence of morally wrong actions. It is open to the fast lane philosopher to say that, if the fast lane strategy also applies to some or all of these other cases, we should follow the argument where it leads.

\footnotetext{
${ }^{12}$ We should not assume that the explanation of how the new language functions has to take place in predicate calculus, or that it must avoid the use of the new resources: see Williamson 1999, forthcoming. ${ }^{13}$ See Baker 1993 for a related point.
} 
Perhaps the fast lane strategy undermines the possibility of any indispensability argument for non-fundamental objects. But there is no need for the fast lane philosopher to make that bold claim. Their position is that appeal to the nominalistic grounds of alleged relations between physical and mathematical objects provides explains the phenomena at least as well as the platonistic alternatives. When applied to other indispensability arguments, this provides a recipe for rival explanations: where reference to Fs is claimed to be explanatorily indispensable, (i) argue that the alleged facts about Fs would be grounded in facts that could obtain even if there were no Fs, and (ii) argue that these F-less facts explain the phenomena at least as well. But both (i) and (ii) are substantial argumentative burdens. Perhaps it cannot be shown that the facts about Fs invoked in the original explanation would be grounded in F-less facts, in which case (i) fails. Part of the difficulty is that even if $F$ s are non-fundamental objects, facts about $F$ s may be fundamental facts. If (i) succeeds, perhaps it cannot be shown that the rival explanation is at least as good as the original, in which case (ii) fails. For instance, perhaps facts about genes are grounded in facts about elementary particles, but the phenomena genes are used to explain cannot be explained so well by elementary particles. The difficulty of steps (i) and (ii) will vary from case to case. Nothing in fast lane nominalism commits its proponents to thinking that their programme can be used to defeat every indispensability argument for non-fundamental objects. The fast lane offers a way of coming up with explanations that merit consideration, not with explanations that are guaranteed to be

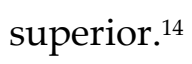

Whilst there is much more to be said, I take it that these responses mean that the worry is not clearly fatal to fast lane nominalism.

I do not know whether the fast lane strategy succeeds or fails. If the strategy succeeds, the indispensability argument is refuted, and a line of response previously thought to be untenable -

\footnotetext{
${ }^{14}$ One may well worry that step (ii) fails in the mathematical case: the graph-theoretic explanation of why noone has ever walked across Königsberg crossing each bridge exactly once seems more explanatory than the explanation appealing to the physical property in virtue of which the graph-theoretic property is instantiated; the nominalistic explanation is messier, less elegant. I am grateful both to an anonymous referee and to my respondent Matteo Plebani for raising this worry (see Plebani 2014, this volume, section 3). It echoes earlier criticisms of inference to the best explanation arguments for moral realism (see e.g. Sayre-McCord 1988: 449, Railton 1998: 179-180). In my 'Multiple realization and expressive power in mathematics and ethics' I discuss this worry and the earlier metaethical arguments in detail. In brief: I suggest that these 'multiple realizability' worries can both be laid to rest if opponents of realism can provide explanations of the phenomena which while remaining non-moral or non-mathematical - are not too specific to forfeit explanatory insight. I argue that realists should think their alleged moral or mathematical facts have grounds which have the right degree of specificity; and that their opponents can and should appeal to these facts in their explanations. So I think that the fast-lane philosopher can deal with the worry provided they are careful to select the appropriate alleged grounds.
} 
the hard road - is vindicated. Moreover, the fast lane strategy is conceptually economical. It makes no appeal to the notions of pretence, make-believe, simulation (Yablo 2001, Leng 2010), weaseling (Melia 2000), or indexing (Melia 2000, Daly and Langford 2009). Neither is there any ('hermeneutic nominalist') claim that this is what our apparently platonistic explanations meant all along. Perhaps the philosophy of mathematics needs some of these concepts for different purposes, such as explaining the utility of mathematics in science and in everyday life. But if the fast lane strategy succeeds, then for the purpose of refuting the indispensability argument, these concepts are superfluous.

If the fast lane strategy fails, that may be significant too. Recall that abstract expressionists are easy road nominalists who claim that mentioning mathematical objects increases our expressive power rather than our explanatory power. If the problem with the fast lane is that the relevant explanations cannot be stated - for instance, the required generalizations cannot be formulated in an acceptable manner - that lends support to abstract expressionism. For if certain inexpressible nominalistic generalizations would be explanatory were they to be expressible, that bolsters the case for thinking that the role of mathematics is expressive rather than explanatory. Putnam (1971: section $\mathrm{V}$ ) may be right: perhaps nominalistic language is inadequate for the statement of our best scientific explanations. But, as abstract expressionists such as Melia emphasize, that does not mean that our best scientific explanations are themselves platonistic (see Melia 1995).

So the fast lane is not only overlooked but significant.

\section{The content challenge to abstract expressionism}

In section 2 I discussed what platonists should say about the grounding of relations between mathematical and non-mathematical objects. I then used the resources revealed in this investigation to help out the hard road response to the indispensability argument. In this section, I will argue that the investigation also has implications for the easy road: specifically, I will use it to provide abstract expressionists with a response to a recent challenge.

First of all, let me introduce the challenge. Colyvan (2010) argues that abstract expressionists have to explain what is conveyed by those scientific theories which mention mathematical objects. Furthermore, he argues that setting this out requires something like a hard road strategy. In Colyvan's view, the easy road is no easier than the hard road.

For instance, Melia (2000) suggests that it is defensible to make claims such as: 
(4) There exists a differentiable function that maps from the space-time manifold to the real numbers, but there are no mathematical objects. ${ }^{15}$

According to Melia, this is not the blatant contradiction it might appear to be, because the first half of the sentence ought not to be interpreted as a platonistic claim: on Melia's view, this piece of platonistic language serves to convey a nominalistic claim. Colyvan's response is straightforward:

I simply do not know what to make of sentences such as (4) where no obvious paraphrase presents itself. ... How does [Melia] respond to someone who simply does not understand sentences like (4), except as the obvious contradiction? One way of clarifying things would be to provide the appropriate translation. Indeed, this is the only way of replying that is acceptable. ... So we see that this easy-road strategy is dependent on the success of a hard-road strategy. (Colyvan 2010: 295-6)

Similar challenges to abstract expressionism are offered by Jason Turner (2011) and Chris Pincock (2012: 252-6; this echoes his 2007: 265-273). The task for the abstract expressionist is to explain what the mathematical claims which figure in scientific theories serve to convey. The abstract expressionist maintains that this it does not imply the existence of mathematical objects - but precisely what is conveyed? Call this the content challenge to abstract expressionism. ${ }^{16}$

Let us begin with an example. Assume that the English sentence 'The table has mass $8 \mathrm{~kg}$ ' is true only if the table bears the has-mass-in-kg-of relation to the number 8 . What nominalistic claim could be conveyed by uttering this sentence? In the light of the preceding discussion, a possible answer is obvious: the claim that the table possesses the nominalistic property has-mass-8-kg (see Melia 2003: 58; Liggins 2012, section 2). However, as Colyvan (2010: 295; 2012, section 5) emphasises, the challenge cannot be met merely by picking off a few easy cases such as this one. Instead, it requires a general response.

I will now argue that my previous discussion provides abstract expressionists with a general response to the content challenge. Where a claim implies the obtaining of a relation between a physical object and a number, the abstract expressionist should ask what grounds the obtaining of this relation. According to the arguments of section 2, the platonist should appeal to a nominalistic

\footnotetext{
15 The example is Colyvan's but strongly echoes Melia 2000: 469.

${ }^{16}$ Explaining how the content is conveyed is also a challenge for abstract expressionism: see Liggins forthcoming for discussion.
} 
property in virtue of which the relation obtains. The abstract expressionist can then say that the claim conveys the following: that the object instantiates that property. (Using the earlier notation, a sentence which seems to say that cRo conveys the claim that R-oc; and similarly in polyadic cases.)

For instance, let $\mathrm{D}$ be the binary relation of being such that there is a differentiable function mapping the former to the latter. If a platonist thinks that our best explanations involve the claim that the space-time manifold bears $D$ to the set of real numbers, then they should think that there is some nominalistic property of the space-time manifold in virtue of which this relation obtains. Call the property ' $E$ '. Then the abstract expressionist can say that 'There exists a differentiable function that maps the space-time manifold to the real numbers' serves to convey the claim that the spacetime manifold has E; and that a nominalist who utters (4) conveys the conjunctive claim that the space-time manifold has $\mathrm{E}$ and there are no mathematical objects.

To give another example, consider the claim 'The physical system $\mathrm{P}$ has phase space $\mathrm{S}^{\prime}{ }^{17}$ The phase space of a system is meant to represent its physically possible configurations, and the physically possible configurations of a system depend on its physical make-up (where this is understood widely so as to include the laws of nature). So the abstract expressionist can claim that 'P has phase space $\mathrm{S}^{\prime}$ conveys that the system $\mathrm{P}$ has a certain physical make-up.

In short, platonists should concede that relations between physical objects and numbers obtain in virtue of physical properties. But then abstract expressionists can appeal to these properties to respond to the content challenge. This does not simply deal with some particular cases, but provides a general response.

\section{Concluding remarks}

Although my aim has been to advance the case for nominalist responses to the indispensability argument, I have been quantifying freely over properties and relations. It is natural to wonder whether this is defensible: have I not said things which imply that nominalism is false?

I have two comments on this worry. First, the topic under discussion here is the existence of mathematical objects such as numbers, which is the conclusion of the indispensability argument. Right at the beginning, I defined 'nominalism' as a claim about mathematical objects. If it turns out that the indispensability argument does not establish the existence of mathematical objects, that is a significant result.

${ }^{17}$ Lyon and Colyvan 2008 discuss such examples. 
My second comment is more speculative. Easy road nominalists maintain that even if mathematics is indispensable to our best explanations, that does not establish the existence of mathematical objects. If they say the same thing about properties, they will maintain that even if quantification over properties is indispensable to our best explanations, that does not establish the existence of properties. Melia 1995 contains remarks pointing in this direction which deserve fuller development. Assume that virtues, if they exist, are properties, and consider the sentence 'There is a virtue which Bill and Ben have in common'. Melia suggests that $(\mathrm{V})$ may serve to convey a truth, even if there are no such things as virtues: the truth expressed by the long disjunction beginning 'Bill is chaste and Ben is chaste; or Bill is honest and Ben is honest; or ...'. It is no coincidence that this view closely parallels abstract expressionism. One way to argue against positing abstract objects is to begin by refuting the indispensability argument, quantifying over properties in the course of doing so, and then argue for an account of property-talk which resembles the easy road strategy. ${ }^{18}$

I have argued that the debate over the indispensability argument can be advanced by using the notion of grounding. Asking grounding questions of platonists reveals resources for nominalists to use (section 2). The hard road response to the indispensability argument is often identified with Field's programme. But once we realize that Field's is only one lane on the road, we can put these resources to work to create an alternative hard road response, the fast lane (section 3). I have argued that the fast lane response is promising, and avoids the chief objections to Field's programme, but that much work remains to be done. If the fast lane response succeeds, it refutes the indispensability argument, and if it fails, its failure may add plausibility to abstract expressionism (section 4). I have also argued that reflection on the metaphysics of quantities supplies a way for abstract expressionists to meet the content challenge (section 5). The notion of grounding is thus a fruitful one to bring to the indispensability debate. The result of doing so is to strengthen nominalism through weakening the indispensability argument. ${ }^{19}$

\section{Works cited}

Baker, Alan 2003. Does the existence of mathematical objects make a difference? Australasian Journal of Philosophy 81: 246-64.

Baker, Alan 2005. Are there genuine mathematical explanations of physical phenomena? Mind 114: 223-38.

\footnotetext{
18 See Balaguer 1998: 13-14 for related remarks.

${ }^{19}$ Thanks to Chris Daly I am particularly grateful to Matteo Plebani for ......
} 
Baker, Alan 2009. Mathematical explanation in science. British Journal for the Philosophy of Science 60: $611-633$.

Baker, Alan and Mark Colyvan 2011. Indexing and mathematical explanation. Philosophia Mathematica 19: 323-334.

Baker, Lynn Rudder 1993. Metaphysics and mental causation. In John Heil and Alfred Mele (eds) Mental Causation. Oxford: Clarendon Press: 75-95.

Balaguer, Mark 1998. Platonism and Anti-Platonism in Mathematics. New York: Oxford University Press.

Balaguer, Mark 2011. Fictionalism in the philosophy of mathematics. In Edward N. Zalta (ed.) Stanford Encyclopedia of Philosophy (Fall 2011 edition).

URL $=<$ http://plato.stanford.edu/archives/fall2011/entries/fictionalism-mathematics/>

Clark, Michael J. and David Liggins 2012. Recent work on grounding. Analysis 72: 812-823.

Colyvan, Mark 2001. The Indispensability of Mathematics. New York: Oxford University Press.

Colyvan, Mark 2010. There is no easy road to nominalism. Mind 119: 285-306.

Colyvan, Mark 2012. Road work ahead: heavy machinery on the easy road. Mind 121: 1031-1046.

Correia, Fabrice and Benjamin Schnieder 2012. Grounding: an opinionated introduction. In their (eds) Metaphysical Grounding: Understanding the Structure of Reality. Cambridge: Cambridge University Press: 1-36.

Crane, Tim 1990. An alleged analogy between numbers and propositions. Analysis 50: 224-30.

Creath, Richard 1980. Nominalism by theft. American Philosophical Quarterly 17: 311-318.

Daly, Chris and Simon Langford 2009. Mathematical explanation and indispensability arguments. Philosophical Quarterly 59: 641-58.

Dasgupta, Shamik 2013. Absolutism vs comparativism about quantities. Oxford Studies in Metaphysics 8.

Davidson, Donald 1965. Theories of meaning and learnable languages. In Yehoshua Bar-Hillel (ed.) Logic, Methodology and Philosophy of Science: Proceedings of the 1964 International Congress. Amsterdam: North-Holland: 383-94.

Field, Hartry 1980. Science without Numbers: A Defence of Nominalism. Oxford: Blackwell.

Field, Hartry 1984. Review of Dale Gottlieb's Ontological Economy: Substitutional Quantification and Mathematics. Nô̂s 18: 160-165.

Field, Hartry 1989. Realism, Mathematics and Modality. Oxford: Blackwell.

Fine, Kit 1995. Ontological dependence. Proceedings of the Aristotelian Society 95: 269-90. 
Hawthorne, John 2006. Quantity in Lewisian metaphysics. In his Metaphysical Essays. Oxford:

Clarendon Press: 229-243.

Horgan, Terence 1984. Science nominalized. Philosophy of Science 51: 529-549.

Horgan, Terence 1989. Attitudinatives. Linguistics and Philosophy 12: 133-165.

Künne, Wolfgang 2006. Properties in abundance. In P. F. Strawson and Arindam Chakrabarti (eds)

Universals, Concepts, and Qualities: New Essays on the Meaning of Predicates. Aldershot, Ashgate: 249-300.

Leng, Mary 2010. Mathematics and Reality. Oxford: Oxford University Press.

Liggins, David 2003. On being twice as heavy. Philosophia Mathematica 11: 203-7.

Liggins, David 2012. Weaseling and the content of science. Mind 121: 997-1005.

Liggins, David (forthcoming). Abstract expressionism and the communication problem. British

Journal for the Philosophy of Science.

Liggins, David MS. Multiple realization and expressive power in mathematics and ethics.

Lyon, Aidan and Mark Colyvan 2008. The explanatory power of phase spaces. Philosophia

Mathematica 16: 227-243.

Lyon, Adian 2012. Mathematical explanations of empirical facts, and mathematical realism.

Australasian Journal of Philosophy 90: 559-78.

MacBride, Fraser 1999. Listening to fictions: a study of Fieldian nominalism. British Journal for the Philosophy of Science 50: 431-55.

Malament, David 1982. Review of Hartry Field's Science without Numbers. Journal of Philosophy 79: $523-34$.

Melia, Joseph 1995. On what there's not. Analysis 55: 223-9.

Melia, Joseph 1998. Field's programme: some interference. Analysis 58: 63-71.

Melia, Joseph 2000. Weaseling away the indispensability argument. Mind 109: 455-479.

Melia, Joseph 2003. Defending the indispensible. Metascience 12: 55-8.

Melia, Joseph 2006. The conservativeness of mathematics. Analysis 66: 202-8.

Meyer, Ulrich 2002. Is science first-order? Analysis 62: 305-308.

Miller, Kristie 2010. Three routes to contingentism in metaphysics. Philosophy Compass 5: 965-77.

Millikan, R.A. 1913. On the elementary electrical charge and the Avogadro constant. Physical Review 2: $109-43$.

Morrison, Joe 2012. Evidential holism and indispensability arguments. Erkenntnis 76: 263-278.

Mundy, Brent 1987. The metaphysics of quantity. Philosophical Studies 51: 29-54.

Nagel, Ernest 1931. Measurement. Erkenntnis 2: 313-333. 
Nolan, Daniel 1997. Impossible worlds: a modest approach. Notre Dame Journal of Formal Logic 38: $535-72$.

Pincock, Christopher 2007. A role for mathematics in the physical sciences. Noûs 41: 253-275.

Pincock, Christopher 2012. Mathematics and Scientific Representation. New York: Oxford University Press.

Plebani, Matteo 2014. Nominalistic content, grounding, and covering generalizations: Reply to 'Grounding and the indispensability argument'. Synthese [this volume]

Putnam, Hilary 1971. Philosophy of Logic. New York: Harper. Reprinted in his 1979 Mathematics, Matter and Method: Philosophical Papers, Volume 1 (2nd. ed.). Cambridge: Cambridge University Press: $323-357$.

Railton, Peter 1998. Moral Explanation and Moral Objectivity. Philosophy and Phenomenological Research 58: $175-182$.

Resnik, Michael D. 1985. How nominalist is Hartry Field's nominalism? Philosophical Studies 47: 16381.

Resnik, Michael D. 1997. Mathematics as a Science of Patterns. Oxford: Clarendon Press.

Rosefeldt, Tobias 2008. 'That'-clauses and non-nominal quantification. Philosophical Studies 137: 30133.

Rosen, Gideon 2010. Metaphysical dependence: grounding and reduction. In Bob Hale and Aviv Hoffmann (eds) Modality: Metaphysics, Logic, and Epistemology. Oxford: Oxford University Press: 109-135.

Sayre-McCord, Geoffrey 1988. Moral theory and explanatory impotence. Midwest Studies in Philosophy 12: 433-57.

Schiffer, Stephen 2003. The Things We Mean. Oxford: Clarendon Press.

Shapiro, Stewart 1983. Conservativeness and incompleteness. Journal of Philosophy 80: 521-531.

Trogdon, Kelly (forthcoming). An introduction to grounding. In Miguel Hoeltje, Benjamin Schnieder, and Alex Steinberg (eds) Dependence. München: Philosophia Verlag.

Turner, Jason 2011. Review of Yablo's Things: Philosophical Papers, Volume 2.

URL=<http://ndpr.nd.edu/news/25473-things-philosophical-papers-volume-2/>

Williamson, Timothy 1999. Truthmakers and the converse Barcan formula. Dialectica 53: 253-270.

Williamson, Timothy 2011. What is naturalism? New York Times (online), 4 September 2011.

$\mathrm{URL}=<$ http://opinionator.blogs.nytimes.com/category/the-stone/>

Williamson, Timothy 2011a. On ducking challenges to naturalism. New York Times (online), 28

September 2011. URL=<http://opinionator.blogs.nytimes.com/category/the-stone/> 
Williamson, Timothy (forthcoming). Logic, metalogic, and neutrality. Erkenntnis.

Yablo, Stephen 2001. Go figure: a path through fictionalism. Midwest Studies in Philosophy 25: 72-102. Yablo, Stephen 2002. Abstract objects: a case study. Philosophical Issues 12: 220-240. 